\title{
Intellectual performance profile of a sample of children and adolescents from Brazil with 22q11.2 Deletion Syndrome (22q11.2DS) based on the Wechsler Scale
}

\section{Perfil de desempenho intelectual de uma amostra brasileira de crianças e adolescentes com Sindrome da Deleção 22q11.2 (22q11.2DS) com base na Escala Wechsler}

\author{
Larissa Salustiano Evangelista PIMENTA ${ }^{1}$ (ID) 0000-0001-5235-7851 \\ Cláudia Berlim de MELLO² iD 0000-0003-3953-3966 \\ Diogo Cordeiro de Queiroz SOARES ${ }^{1}$ ID 0000-0002-6589-2367 \\ Anelisa Gollo DANTAS ${ }^{3}$ iD) 0000-0003-0594-6762 \\ Maria Isabel MELARAGNO3 ${ }^{3}$ iD) 0000-0002-4344-9698 \\ Leslie Domenici KULIKOWSKI ${ }^{4}$ ID 0000-0003-2236-3956 \\ Chong Ae KIM ${ }^{1}$ iD 0000-0002-1754-1300
}

\begin{abstract}
The 22q11.2 Deletion Syndrome (22q11.2DS), the most common human chromosome microdeletion syndrome, is associated with a very heterogeneous neurocognitive phenotype. One of the main characteristics of the syndrome spectrum is the intellectual variability, which encompasses average performance and intellectual disability and discrepancies between Verbal Intelligence Quotient and Performance Verbal Intelligence Quotient, with greater impairment in nonverbal tasks.

1 Universidade de São Paulo, Faculdade de Medicina, Departamento de Pediatria. São Paulo, SP, Brasil.

2 Universidade Federal de São Paulo, Faculdade Paulista de Medicina, Departamento de Psicobiologia. R. Botucatu, 862, 1ํ. Andar, Vila Clementino, 04023-062, São Paulo, SP, Brasil. Correspondência para/Correspondence to C.B. MELLO. E-mail: <cberlimmello@gmail.com>.

${ }^{3}$ Universidade Federal de São Paulo, Departamento de Morfologia e Genética, Divisão de Genética. São Paulo, SP, Brasil.

${ }^{4}$ Universidade de São Paulo, Faculdade de Medicina, Departamento de Patologia. São Paulo, SP, Brasil. Support: This study was financed in part by the Conselho Nacional de Desenvolvimento Científico e Tecnológico (Process n 475154/2012-6) and Coordenação de Aperfeiçoamento de Pessoal de Nivel Superior.

Article based on the dissertation of L.S.E. PIMENTA, entitled "Avaliação neurocognitiva e comportamental da Síndrome da Deleção 22q11.2". Universidade de São Paulo, 2018.

$\boldsymbol{\nabla} \boldsymbol{\nabla} \boldsymbol{\nabla}$

Como citar este artigo/How to cite this article

Pimenta, L. S. E., Mello, C. B., Soares, D. C. Q., Dantas, A. G., Melaragno, M. I., Kulikowski, L. D., \& Kim, C. A. (2019). Intellectual performance profile of a sample of children and adolescents from Brazil with 22q11.2 Deletion Syndrome (22q11.2DS) based on the Wechsler Scale. Estudos de Psicologia (Campinas), 36, e180101. http://dx.doi.org/10.1590/1982-0275201936e180101
\end{abstract}


The present study aimed at investigating the intellectual performance aspects of a 21children and adolescents sample from Brazil who had been diagnosed with 22q11.2DS, based on the Wechsler Intelligence Scale for Children - $4^{\text {th }}$ edition. The samples were reviewed considering the differences between indices. The results revealed an Full Scale Intelligence Quotient predominant in the borderline range (42 to 104) and a significant discrepancy between the indices of Verbal Comprehension and Perceptual Reasoning in $42 \%$ of the sample. With regard to the performance in the subtests alone, a better performance was found in Similarities, whereas block design, matrix reasoning, digit span and letter-number sequencing subtests were the most challenging. These findings indicate that a comprehensive assessment of intellectual performance aspects covering the different measures of the Wechsler Intelligence Scale may contribute to a broader understanding of the neurocognitive phenotype associated with 22q11.2DS.

Keywords: DiGeorge syndrome; Genetics, behavioral; Neuropsychology; Wechsler Scales.

\section{Resumo}

A Sindrome da Deleção 22q11.2 (SD22q11.2), microdeleção cromossômica mais frequente em humanos, é associada a um fenótipo neurocognitivo muito heterogêneo. Uma das principais características do espectro da síndrome é a variabilidade intelectual, que abrange de desempenho médio a deficiência intelectual, bem como discrepâncias entre Quociente de Inteligência Verbal e de Quociente de Inteligência de Execução, com maior prejuízo nas tarefas não verbais. O presente estudo teve por objetivo investigar aspectos do desempenho intelectual de uma amostra brasileira de 21 crianças e adolescentes diagnosticados com SD22q11.2, com base nos indicadores da Wechsler Intelligence Scale for Children - $4^{\text {th }}$ edition. As amostras foram analisadas considerando diferenças entre os índices. Os resultados revelaram predomínio de Quociente de Inteligência Total na faixa limitrofe, entre 42 e 104, assim como discrepância significativa entre os índices de compreensão verbal e organização perceptual em $42 \%$ da amostra. No que concerne ao desempenho nos subtestes de forma isolada, um melhor resultado foi verificado em semelhanças, ao passo que cubos, raciocínio matricial, dígitos e sequência de números e letras foram os mais desafiadores. Esses achados indicam que uma avaliação abrangente de aspectos do desempenho intelectual contemplando as diversas medidas da Escala Wechsler de Inteligência pode contribuir para uma compreensão mais ampla do fenótipo neurocognitivo associado à SD22q11.2.

Palavras-chave: Síndrome de DiGeorge; Genética comportamental; Neuropsicologia; Escalas de Wechsler.

The 22q11.2 Deletion Syndrome (22q11.2DS), also known as DiGeorge syndrome or Velo-cardio-facial syndrome, is associated with the deletion of region 11.2 of the long arm of chromosome 22 and involves a spectrum of over 180 clinical, physical and behavioral manifestations (Shprintzen, 2008). It is described as the most common microdeletion syndrome found in the population, with an incidence of approximately 1:2.000 to 1:4.000 live births (McDonald-McGinn et al., 2015; Zhao et al., 2018).

The 22q11.2DS is characterized in particular by the presence of psychiatric disorders. Affected individuals exhibit higher rates of psychiatric comorbidities compared to the general population (Radoeva, 2017; Schneider et al., 2014a). About one third of the adult population with 22q11.2DS develops some kind of psychiatric disorder (Gothelf et al., 2013). Schizophrenia incidence is of particular interest as it is described in over $20 \%$ of cases (Tang et al., 2014a). Anxiety disorder, depression and bipolar mood disorder have also been reported (Fabbro, Rizzi, Schneider, Debbane, \& Eliez, 2012; Tang et al., 2014a; Tang et al., 2014b; Zarchi et al., 2014). In studies with children, internalizing kind of behaviors such as anxiety symptoms as well as difficulties in social interaction with peers, affective and attention problems have been described (Antshel et al., 2006; Schonherz et al., 2014). There are also reports of high rates of Attention Deficit Hyperactivity Disorder (Hidding et al., 2015) and Autism Spectrum Disorder (Antshel et al., 2007; Bink et al., 2014; McCabe et al., 2013; Schneider et al., 2014b).

As to the neurocognitive phenotype, studies have indicated that intellectual performance varies, in general, between the borderline range and the lower average functioning, that is, Intelligence Quotients (IQ) range between 70 and 85 in the Wechsler Scales (Jacobson et al., 2010). Mild to moderate intellectual disability (IQ 55 to 70) occurs in more than 40\% of the cases (De Smedt et al., 2007; Niklasson, Rasmussen,

2 Óskarsdóttir, \& Gillberg, 2009). Approximately $75 \%$ of patients have a significant discrepancy of approximately 
15 points between the Verbal (VIQ) Scale and the Performance (PIQ) Scale, with accrued performance impairment. Further, associated with the syndrome neurocognitive phenotype, cognitive functions deficits occur in visospatial memory, time perception and spatial orientation, and poor performance in mathematics (De Smedt et al., 2007; Furniss, Biswas, Gumber, \& Singh, 2011; Niklasson et al., 2009; Wong, Riggins, Harvey, Cabaral, \& Simon, 2014)

Cross-sectional and longitudinal studies in individuals with 22q11.2DS have reported a negative correlation between age and IQ (Duijff et al., 2013; Green et al., 2009; Niklasson et al., 2009). A reduction in Wechsler Scale indexes over the years is likely due to a decline in Verbal IQ, due to the greater fragility in the development of expressive language (Gothelf et al., 2005). Other studies have suggested that the apparent verbal deterioration would be associated with changes in the thickness of cortical structures that support neurocognitive functioning and may predispose to the onset of psychiatric symptoms.

Because it is an intellectual profile with great heterogeneity, characterization using the Wechsler Scales is continuously seen in studies of psychiatric and behavioral phenotypes of 22q11.2DS, due both to their reliability coefficients and diagnostic accuracy, as well as to the possibilities of use in clinical populations. However, a more detailed analysis of the scale indices, discrepancies and subtests, relevant for a deeper design of the cognitive aspects in this population, has been scarcely used in the studies.

In an article with emphasis on the use of the Wechsler Scale subtests for neuropsychological assessment, Simões (2002) described the importance of using all factor indexes of the scale for the development of an individual's cognitive profile and for the raising of hypothesis about its neuropsychological functioning. In addition, that author highlighted the relevance of weighted score analysis in the subtests. From the interpretation of the performance in each subtest, it is possible to highlight cognitive areas with greater potentiality and those with greater weakness compared to normalized groups.

This study aimed at investigating aspects of the neurocognitive phenotype of 22q11.2DS from an analysis of the intellectual performance of a sample from Brazil of children and adolescents with this diagnosis, taking into account the indicators of the Wechsler's Intelligence Scale for Children - $4^{\text {th }}$ edition (WISC-IV).

\section{Method}

\section{Participants}

The sample of this study included 21 children and adolescents, aged between seven and fifteen years, with an average of 11.9 years (Standard Deviation $[S D]=2.2$ ) and included both genders, recruited from the outpatient clinic of the Medical Genetics Unit of the Instituto da Criança do Hospital das Clínicas da Faculdade de Medicina da Universidade de São Paulo and of the Center of Medical Genetics of Escola Paulista de Medicina da Universidade Federal de São Paulo. All the patients were clinically diagnosed by a geneticist; the diagnosis was confirmed by molecular examination Multiplex Ligation-dependent Probe Amplification (MLPA). Only individuals with typical 3Mb deletion in region 22q11.2 were enrolled.

This study was approved by the Research Ethics Committee of the Medicine Facultedy, Universidade de São Paulo (case 1088/43/12). All patients or their guardians signed an informed consent form.

Twenty-four patients were initially recruited; however, three were unable to perform the tasks of the scale due to significant cognitive impairments and, consequently, were not enrolled. The final sample, therefore, consisted of twenty-one participants, of which thirteen were males (38\%). Twelve of the 21 participants attended public schools, eight attended private schools and one did not go to school, due to a family's decision on account of difficulties in educational adaptation and accessibility of the school facilities. The guardians of all participants reported school problems, especially in math and text interpretation. 


\section{Procedures}

Intellectual performance was assessed using the Wechsler's Intelligence Scale for Children, $4^{\text {th }}$ Edition (WISC-IV), validated in the Brazilian population (Wechsler, 2013). This is an individual's clinical assessment instrument designed to assess the intellectual capacity and problem-solving process of children aged six to 16 years and 11 months.

The scale is composed of four core indices measured in composite scores (average IQ 90-109), which comprise principal and supplemental subtests in weighted scores (1-19). The first is the Verbal Comprehension Index (VCI), which includes the Similarities, Vocabulary, and Comprehension subtests. Supplemental subtests include Information and Word Reasoning. The second is the Perceptual Reasoning Index (PRI), composed by the Block Design, Picture Concepts, and Matrix Reasoning subtests; the supplemental index is Picture Completion. The third index is Working Memory Index (WMI), and its subtests include Digit Span, LetterNumber Sequencing; the supplemental index is Arithmetic. Finally, the fourth index is the Processing Speed Index (PSI); the subtests are Coding, Symbol Search and the supplemental index is Cancellation (Wechsler, 2013).

In this study, only the 10 core subtests of each index were used for patient's assessment. Their application was performed individually in a single two-hour session by the same psychologist and also by a psychologist duly trained in the application of the scale, in order to avoid any biases in the test performance.

To investigate the phenotypic profile regarding intellectual performance, the following measures were used: (1) factor measures indexes (composite point of index and weighted score of the 10 core subtests of the scale); (2) discrepancies between the compound score in the factor indexes and their cumulative frequency; (3) weighted score discrepancies among six of the ten subtests (Digit Span, Letter-Number Sequencing, Coding, Symbol Search, Similarities, and Picture Concepts), and their cumulative frequency; and (4) Determination of easiness and difficulties in comparing the top 10 subtests of the scale.

The analysis of the factor indexes is performed after the conversion of the gross score by the weighted score according to the scale normatization tables taking into account the patient's age. The composite score of the indexes is calculated by adding the weighted score of the subtests of their domain, also provided in the scale normatization tables described in the directions manual.

In order to verify any discrepancy between the indexes, the subtraction of the composite scores is required; the absolute value of the difference is compared to a critical value. Both the critical value for each comparison as well as the accumulated frequency are found in the tables provided by the scale. The same process is performed for the analysis of discrepancies between the subtests; however, in this case, the subtraction is between the weighted scores. On the other hand, difficulties and facility are analyzed by summing up the weighted points of the 10 core subtests, and the main value of this result is compared to a critical value. This critical value and the accumulated frequency are obtained from the scale tables.

Descriptive statistics with frequency and dispersion measures (mean and standard deviation with relevant confidence intervals) were used. Data were analyzed using the SPSS Statistical Software, version 13.0 for Windows.

\section{Results}

With regard to the neurocognitive profile of the participants assessed, as inferred by the analysis of the WISC-IV Scale indexes, the results showed that the mean Full Scale Intelligence Quotient (FSIQ) of the sample was in the borderline range. $73.0(S D=15.2)$. The highest index found was in the middle range 4 (FSIQ104) and the lower index (FSIQ42) was consistent with the intellectual disability classification, 
that is, two standard deviations below the general average of the Brazilian population according to age (Table 1).

As to the other indicators reviewed, the mean perceptual reasoning index (PRI-/M $=75.7)$, the processing speed index (PSI/M = 78.0) and the working memory index (WMI/M = 73.2) were in the borderline range. However, the index that evaluated verbal comprehension $(\mathrm{VCl} / \mathrm{M}=82.7)$ remained at average levels.

The review of the weighted score medians of each subtest of the scale showed that the lowest results were observed in the Block Design (5), Matrix Reasoning (4), Digit Span (5) and Letter-Number Sequencing (5) subtests. The Block Design and Matrix Reasoning subtests are associated with the index that evaluates Perceptual Reasoning, while the Digit Span and Letter-Number Sequencing subtests are associated with the index that assesses Working Memory. On the other hand, the highest results were found in the Similarities (8) subtest, referring to the index that evaluates Verbal Comprehension. Observing the standard deviation of the subtests, a low amplitude dispersion profile is observed, indicating a greater homogeneity in the group performance.

With regard to the analysis of the discrepancy frequencies between indexes (Table 2), the results showed that in all 12 comparisons there was at least one significant difference, i.e., greater than 15 points. In the comparison between the factor indexes, the highest occurrence of discrepancies (9/21) was observed between the Verbal Comprehension and the Perceptual Reasoning ( $\mathrm{VCI}>\mathrm{PRI}$ ) indexes, with an average difference of 19.4 points. In other words, in $42.9 \%$ of the cases a better performance in the tasks that evaluated verbal aspects of cognition was observed. Significant discrepancies between Verbal Comprehension

Table 1

Intellectual profile of the sample of patients with 22q11.2DS according to the results of the main indices (composite point) and subtests (weighted point) of the WISC-IV Scale

\begin{tabular}{|c|c|c|c|c|c|}
\hline Sociodemographic and intellectual variables & Minimum & Maximum & Average & $S D$ & $M$ \\
\hline Age in years & 7 & 15 & 12.1 & 2.3 & 13 \\
\hline Total IQ & 42 & 104 & 73.0 & 15.2 & 69 \\
\hline \multicolumn{6}{|l|}{ Indexes } \\
\hline Verbal Comprehension & 49 & 119 & 82.7 & 17.6 & 80 \\
\hline Working Memory & 45 & 109 & 73.2 & 18.1 & 71 \\
\hline Processing Speed & 45 & 111 & 78.0 & 17.2 & 82 \\
\hline \multicolumn{6}{|l|}{ Subtests } \\
\hline Block Design & 1 & 11 & 5.7 & 2.9 & 5 \\
\hline Similarities & 3 & 15 & 8.0 & 3.3 & 8 \\
\hline Picture Concepts & 1 & 12 & 7.2 & 2.7 & 7 \\
\hline Coding & 1 & 13 & 6.1 & 3.4 & 6 \\
\hline Vocabulary & 1 & 13 & 6.8 & 3.4 & 7 \\
\hline Letter-Number Sequencing & 1 & 12 & 5.6 & 3.3 & 5 \\
\hline Matrix Reasoning & 2 & 12 & 5.4 & 3.0 & 4 \\
\hline Comprehension & 1 & 12 & 7.1 & 2.9 & 7 \\
\hline Symbol Search & 1 & 11 & 6.3 & 3.0 & 7 \\
\hline
\end{tabular}

Note: M: Median; SD: Standard Deviation; IQ: Intelligence Quotients; WISC-IV: Wechsler's Intelligence Scale for Children - ${ }^{\text {th }}$ edition. 
Index and Working Memory Index ( $\mathrm{VCl}>\mathrm{WMI})$ and Working Memory Index and Processing Speed Index (WMI > PSI) also occurred in 8/21 cases assessed. Again, better developed skills appear in verbal compared to non-verbal tasks.

Observing the frequency of scale index discrepancies in Table 2, it may be noticed that when significant discrepancies (> 15 points) occur, the discrepancy accumulated frequency was less than $17 \%$. That is, when comparing the results obtained in the study, an intrinsic characteristic of the sample studied is observed and not of the general population used in the scale normalization.

When comparing the discrepancies between the six subtests (digit span, letter-number sequencing, coding, symbol search, similarities and picture concepts), the number of cases with significant differences was not large (3/21).

As for the results of analyses that sought to identify the easiness and difficulties associated with intellectual performance considering the average among the ten subtests of each participant compared to the overall average of the scale normalization, there were few significant differences (Table 3).

Four of the 21 patients assessed performed more easily in a single subtest, the Similarities subtest, compared to the other nine subtests evaluated. The subtest in question is associated with the Verbal Comprehension index. On the other hand, 4/21 assessed participants experienced higher levels of difficulty in the Block Design and Matrix Reasoning subtests compared to the others subtests applied. Such subtests evaluate cognition nonverbal aspects.

Table 2

Frequency of discrepancies in 22q11.2DS patients regarding the indexes (composite point) and subtests (weighted point) of the WISC-IV Scale

\begin{tabular}{|c|c|c|c|c|}
\hline \multirow{2}{*}{ Indexes } & \multirow{2}{*}{$\mathrm{n}$} & \multicolumn{2}{|c|}{ Significant Difference } & \multirow{2}{*}{ Cumulative frequency (\%) } \\
\hline & & Average & $S D$ & \\
\hline \multicolumn{5}{|l|}{ Indexes } \\
\hline $\mathrm{VCl}>\mathrm{PRI}$ & 9 & 19.4 & 10.4 & 12.5 \\
\hline $\mathrm{PRI}>\mathrm{VCl}$ & 1 & 14.0 & 0.0 & 16.3 \\
\hline $\mathrm{VCl}>\mathrm{WMI}$ & 8 & 24.3 & 12.5 & 9.6 \\
\hline $\mathrm{WMI}>\mathrm{VCl}$ & 1 & 15.0 & 0.0 & 16.8 \\
\hline $\mathrm{VCI}>\mathrm{PSI}$ & 6 & 31.8 & 14.5 & 9.0 \\
\hline $\mathrm{PSI}>\mathrm{VCl}$ & 3 & 25.7 & 8.4 & 9.0 \\
\hline $\mathrm{PRI}>\mathrm{WMI}$ & 3 & 20.0 & 5.7 & 9.6 \\
\hline WMI > PRI & 2 & 20.0 & 2.0 & 7.6 \\
\hline$P R I>P S I$ & 4 & 21.5 & 5.9 & 11.4 \\
\hline PSI > PRI & 6 & 20.5 & 4.2 & 11.1 \\
\hline WMI > PSI & 8 & 18.1 & 5.6 & 16.1 \\
\hline PSI > WMI & 5 & 26.2 & 12.6 & 11.9 \\
\hline \multicolumn{5}{|l|}{ Subtests } \\
\hline LNS > DS & 0 & 0.0 & & 0.0 \\
\hline DS $>$ LNS & 0 & 0.0 & & 0.0 \\
\hline$C D>S S$ & 1 & 4.0 & 0.0 & 7.8 \\
\hline$S S>C D$ & 3 & 4.3 & 5.0 & 7.5 \\
\hline$S M>P C$ & 2 & 8.0 & 5.0 & 0.0 \\
\hline $\mathrm{PC}>\mathrm{SM}$ & 1 & 4.0 & 0.0 & 3.0 \\
\hline
\end{tabular}

Note: CD: Coding; DS: Digit Span; LNS: Letter-Number Sequencing; PC: Picture Concepts; PRI: Perceptual Reasoning Index; PSI: Processing Speed Index; SD: Standard Deviation; SM: Similarities; SS: Symbol Search; VCl: Verbal Comprehension Index; WMI: Working Memory Index; WISC-IV: Wechsler's Intelligence Scale for Children - $4^{\text {th }}$ edition. 
Determination of sample easiness and difficulties in WISC-IV Scale subtests (weighted point)

\begin{tabular}{|c|c|c|c|c|}
\hline \multirow{2}{*}{ Subtests } & \multirow{2}{*}{$n$} & \multicolumn{2}{|c|}{ Mean Difference } & \multirow{2}{*}{ Cumulative frequency (\%) } \\
\hline & & Average & $S D$ & \\
\hline \multicolumn{5}{|l|}{ Easiness } \\
\hline Similarities & 4 & 5.2 & 2.0 & 4.5 \\
\hline Digit Span & 2 & 2.9 & 0.3 & 25.0 \\
\hline Picture Concepts & 1 & 4.3 & 0.0 & 5.0 \\
\hline Coding & 2 & 4.9 & 0.8 & 7.5 \\
\hline Symbol Search & 1 & 3.7 & 0.0 & 10.0 \\
\hline \multicolumn{5}{|l|}{ Difficulties } \\
\hline Block Design & 4 & 3.7 & 0.5 & 8.8 \\
\hline Similarities & 1 & 3.0 & 0.0 & 10.0 \\
\hline Digit Span & 3 & 4.1 & 1.0 & 11.7 \\
\hline Picture Concepts & 1 & 4.7 & 0.0 & 5.0 \\
\hline Coding & 2 & 5.8 & 1.7 & 5.5 \\
\hline Vocabulary & 1 & 5.3 & 0.0 & 1.0 \\
\hline Letter-Number Sequencing & 2 & 3.6 & 0.3 & 10.0 \\
\hline Matrix Reasoning & 4 & 3.3 & 1.0 & 10.0 \\
\hline Symbol Search & 1 & 4.7 & 0.0 & 5.0 \\
\hline
\end{tabular}

Note: SD: Standard Deviation; WISC-IV: Wechsler's Intelligence Scale for Children - $4^{\text {th }}$ edition.

\section{Discussion}

The main objective of this study was to identify the intellectual performance profile of a sample of children and adolescents with 22q11.2DS based on the WISC-IV Scale Indices. Thus, it was intended to contribute to a better characterization of the neurocognitive profile in this clinical condition, as well as to enhance the importance of using the extended analysis of this instrument.

The results showed an average Intelligence Quotient in the borderline range (FSIQ 73.0 SD = 15.2), with variability from 42 to 104 . These results are consistent with the findings of De Smedt et al. (2007), which showed a variable FSIQ between 50 and 109 in the sample they investigated, and average performance in the borderline range (FSIQ $73.5 S D=11.7)$. Therefore, our findings are associated with previous reports that indicate that the intellectual performance in 22q11.2DS ranges from the middle range (FSIQ $>85)$ to mild to moderate intellectual disability, between 69 and 35 (De Smedt et al., 2007; Jacobson et al., 2010).

Analysis of discrepancies between the Verbal Comprehension and Perceptual Organization Indices $(\mathrm{VCl}<\mathrm{PRI})$ revealed more significant difficulties in nonverbal tasks compared to tasks requiring verbal skills. In the study by De Smedt et al. (2007) 75 of the 103 children diagnosed with 22q11.2DS had higher Verbal IQ (VIQ) than Performance IQ (PIQ). This apparent characteristic of the 22q11.2DS cognitive phenotype consisting of discrepancies between verbal and nonverbal abilities was also found in other studies using neuropsychological tests, which revealed better performance in verbal than visuospatial tests, and in reading than in mathematics (De Smedt et al., 2007; Furniss et al., 2011; Niklasson et al., 2009; Wong et al., 2014). Significant discrepancy between VIQ and PIQ is also described in Williams Syndrome, a microdeletion syndrome involving chromosome 7, which causes intellectual disability, among other findings (Zarchi et al., 2014).

Regarding the analysis of weighted scores on the WISC-IV Scale, the subtests with the lowest scores were Block Design and Matrix Reasoning, associated with the Perceptual Reasoning Index, Digit Span and 
Letter-Number Sequencing, in connection with the Working Memory Index. The functions involved in these subtests, therefore, appear to constitute the most fragile cognitive areas in the 22q11.2DS patients. Working memory deficits have been described in previous studies as a feature of children with 22q11.2DS, as well as executive functioning and visual attention (Campbell et al., 2010). There are also reports of changes in visuospatial skills, including poor mental representation of spatial and temporal information (Campbell et al., 2010; Simon et al., 2008).

Thus, the overall results indicate that the cognitive profile in 22q11.2DS patients is associated in particular with significant weaknesses in measures of fluid intelligence (such as Matrix Reasoning), nonverbal visuospatial processing and organization skills, visual and motor coordination, nonverbal problem solving, verbal memory, attention, auditory coding and processing, and working memory (short-term verbal memorization and mental manipulation of information). On the other hand, the Processing Speed index was in the average classification borderline. Such index is associated with cognitive flexibility involvement (Wechsler, 2013). Investigations with 22q11.2DS patients suggests that deficiencies in cognitive functions such as processing speed, visual memory and facial recognition are associated with the development of negative and paranoid symptoms. (Bassett et al., 2011). With regard to our sample, though, such function was not the most impaired. The best results from our sample were observed in the subtests that evaluated Verbal Reasoning and Concept Formation, indicating that these are the skills with greatest potential in this syndrome (Simões, 2002; Wechsler, 2013).

In essence, the results of the present study corroborate previous findings in the identification of an intellectual performance variability profile in 22q11.2DS patients in the course of childhood and adolescence, with better performance in the nonverbal domain compared to the verbal domain. Comparative analyses of factor indexes also enhance the adequacy of the WISC-IV Scale in the phenotypic characterization of patients with genetic syndromes that present cognitive impairment. Identification of more fragile cognitive skills can substantially contribute to directing the long-term therapeutic and pedagogical approach. It is also important to highlight that in contexts where a broader neuropsychological assessment is not feasible, the scale can be of great value as it is a widely used tool among psychologists.

Although the main objective of this study was to describe the intellectual performance of a sample of children and adolescents in Brazil with 22q11.2DS based on the WISC-IV Scale indicators, one of the limitations of this study was that it did not consider clinical aspects, such as the presence of psychiatric symptoms and sociodemographic factors, such as family income or educational level, that could contribute to a broader reflection on the observed profile. Since patients have been recruited from high-demand public services, difficulties are often encountered for inter-consultations for psychiatric investigations. Moreover, the sample distribution was not matched by age group, since it is a convenience sample.

However, despite such limitations, the study contributes to the literature on cognitive phenotype in 22q11.2DS patients by presenting results that confirm the existence of performance discrepancies between verbal and nonverbal tasks in individuals with that diagnosis. Studies in this perspective can contribute to a better understanding of the genotype / phenotype relationship, as well as deficits and preserved skills, and foster interventions specifically geared to the weaknesses of individuals with this diagnosis.

\section{Contributors}

L.S.E. PIMENTA, C.B. MELLO, and C.A. KIM contributed to the study conception and design, data analysis and interpretation, review and final approval of the article. D.C.Q. SOARES, A.G. DANTAS, L.D. KULIKOWSKI and M.I. MELARAGNO contributed to the conception and design of the study, analysis and interpretation of the data. 


\section{References}

Antshel, K. M., Aneja, A., Strunge, L., Peebles, J., Fremont, W. P., Stallone, K., ... Kates, W. R. (2007). Autistic spectrum disorders in velo-cardio facial syndrome (22q11.2 Deletion). Journal of Autism and Developmental Disorders, 37(9), 1776-1786. http://dx.doi.org/10.1007/s10803-006-0308-6

Antshel, K. M., Fremont, W., Roizen, N. J., Shprintzen, R., Higgins, A. M., Dhamoon, A., \& Kates, W. R. (2006). ADHD, major depressive disorder, and simple phobias are prevalent psychiatric conditions in youth with velocardiofacial syndrome. Journal of the American Academy of Child \& Adolescent Psychiatry, 45(5), 596-603. http://dx.doi. org/10.1097/01.chi.0000205703.25453.5a

Bassett, A. S., McDonald-McGinn, D. M., Devriendt, K., Digilio, M. C., Goldenberg, P., Habel, A., ... Zackai, E. H. (2011). Practical guidelines for managing patients with 22q11.2 deletion syndrome. Journal of Pediatrics, 159(2), 332-3399. e1. http://dx.doi.org/10.1016/j.jpeds.2011.02.039

Bink, M., van Boxtel, G. J. M., Popma, A., Bongers, I. L., Denissen, A. J. M., \& van Nieuwenhuizen, C. (2014). EEG theta and beta power spectra in adolescents with ADHD versus adolescents with ASD+ADHD. European Child and Adolescent Psychiatry, 24(8), 873-886.http://dx.doi.org/10.1007/s00787-014-0632-x

Campbell, L. E., Azuma, R., Ambery, F., Stevens, A., Smith, A., Morris, R. G., ... Murphy, K. C. (2010). Executive functions and memory abilities in children with 22q11.2 deletion syndrome. Australian \& New Zealand Journal of Psychiatry, 44(4), 364-371. http://dx.doi.org/10.3109/00048670903489882

De Smedt, B., Devriendt, K., Fryns, J.-P., Vogels, A., Gewillig, M., \& Swillen, A. (2007). Intellectual abilities in a large sample of children with velo-cardio-facial syndrome: An update. Journal of Intellectual Disability Research, 51(9), 666-670. http://dx.doi.org/10.1111/j.1365-2788.2007.00955.x

Duijff, S. N., Klaassen, P. W. J., Swanenburg de Veye, H. F. N., Beemer, F. A., Sinnema, G., \& Vorstman, J. A. S. (2013). Cognitive and behavioral trajectories in 22q11DS from childhood into adolescence: A prospective 6-year follow-up study. Research in Developmental Disabilities, 34(9), 2937-2945. http://dx.doi.org/10.1016/j.ridd.2013.06.001

Fabbro, A., Rizzi, E., Schneider, M., Debbane, M., \& Eliez, S. (2012). Depression and anxiety disorders in children and adolescents with Velo-Cardio-Facial Syndrome (VCFS). European Child \& Adolescent Psychiatry, 21(7), 379-385. http:// dx.doi.org/10.1007/s00787-012-0273-x

Furniss, F., Biswas, A. B., Gumber, R., \& Singh, N. (2011). Cognitive phenotype of velocardiofacial syndrome: A review. Research in Developmental Disabilities, 32(6), 2206-2213. http://dx.doi.org/10.1016/j.ridd.2011.05.039

Gothelf, D., Eliez, S., Thompson, T., Hinard, C., Penniman, L., Feinstein, C., ... Reiss, A. L. (2005). COMT genotype predicts longitudinal cognitive decline and psychosis in 22q11.2 deletion syndrome. Nature Neuroscience, 8(11), 1500-1502. http://dx.doi.org/10.1038/nn1572

Gothelf, D., Schneider, M., Green, T., Debbané, M., Frisch, A., Glaser, B., ... Eliez, S. (2013). Risk factors and the evolution of psychosis in 22q11.2 deletion syndrome: A longitudinal 2-site study. Journal of the American Academy of Child \& Adolescent Psychiatry, 52(11), 1192-1203.e3. http://dx.doi.org/10.1016/j.jaac.2013.08.008

Green, T., Gothelf, D., Glaser, B., Debbane, M., Frisch, A., Kotler, M., ... Eliez, S. (2009). Psychiatric disorders and intellectual functioning throughout development in velocardiofacial (22q11.2 deletion) syndrome. Journal of the American Academy of Child \& Adolescent Psychiatry, 48(11), 1060-1068. http://dx.doi.org/10.1097/CHI.0b013e3181b76683

Hidding, E., Swaab, H., Sonneville, L. M. J., Engeland, H., Sijmens-Morcus, M. E. J., Klaassen, P. W. J., ... Vorstman, J. A. S. (2015). Intellectual functioning in relation to autism and ADHD symptomatology in children and adolescents with 22q11.2 deletion syndrome. Journal of Intellectual Disability Research, 59(9), 803-815. http://dx.doi.org/10.1111/ jir.12187

Jacobson, C., Shearer, J., Habel, A., Kane, F., Tsakanikos, E., \& Kravariti, E. (2010). Core neuropsychological characteristics of children and adolescents with 22q11.2 deletion. Journal of Intellectual Disability Research, 54(8), 701-713. http:// dx.doi.org/10.1111/j.1365-2788.2010.01298.x

McCabe, K. L., Melville, J. L., Rich, D., Strutt, P. A., Cooper, G., Loughland, C. M., .. Campbell, L. E. (2013). Divergent patterns of social cognition performance in autism and 22q11.2 deletion syndrome (22q11DS). Journal of Autism and Developmental Disorders, 43(8), 1926-1934. http://dx.doi.org/10.1007/s10803-012-1742-2

McDonald-McGinn, D. M., Sullivan, K. E., Marino, B., Philip, N., Swillen, A., Vorstman, J. A. S., ... Bassett, A. S. (2015). 22q11.2 deletion syndrome. Nature Reviews Disease Primers, 1, 15071. http://dx.doi.org/10.1038/nrdp.2015.71

Niklasson, L., Rasmussen, P., Óskarsdóttir, S., \& Gillberg, C. (2009). Autism, ADHD, mental retardation and behavior problems in 100 individuals with 22q11 deletion syndrome. Research in Developmental Disabilities, 30(4), 763-773. http://dx.doi.org/10.1016/J.RIDD.2008.10.007 
Radoeva, P. D. (2017). 22q11.2 deletion syndrome: Characterization of psychosis spectrum and future directions. Biological Psychiatry, 82, e5-e7. http://dx.doi.org/10.1016/j.biopsych.2017.04.002

Schneider, M., Schaer, M., Mutlu, A. K., Menghetti, S., Glaser, B., Debbané, M., \& Eliez, S. (2014a). Clinical and cognitive risk factors for psychotic symptoms in 22q11.2 deletion syndrome: A transversal and longitudinal approach. European Child \& Adolescent Psychiatry, 23(6), 425-436. http:/dx.doi.org/10.1007/s00787-013-0469-8

Schneider, M., Debbané, M., Bassett, A. S., Chow, E. W. C., Fung, W. L. A., van den Bree, M., ... Eliez, S. (2014b). Psychiatric disorders from childhood to adulthood in 22q11.2 deletion syndrome: Results from the international consortium on brain and behavior in 22q11.2 deletion syndrome. The American Journal of Psychiatry, 171(6), 627-639. http://dx.doi.org/10.1176/appi.ajp.2013.13070864

Schonherz, Y., Davidov, M., Knafo, A., Zilkha, H., Shoval, G., Zalsman, G., ... Gothelf, D. (2014). Shyness discriminates between children with 22q11.2 deletion syndrome and Williams syndrome and predicts emergence of psychosis in 22q11.2 deletion syndrome. Journal of Neurodevelopmental Disorders, 6(1), 3. http://dx.doi.org/10.1186/18661955-6-3

Shprintzen, R. J. (2008). Velo-cardio-facial syndrome: 30 years of study. Developmental Disabilities Research Reviews, 14, 3-10. http://dx.doi.org/10.1002/ddrr.2

Simões, M. R. (2002). Utilizações da WISC-III na avaliação neuropsicológica de crianças e adolescentes. Paideia, 12(23), 113-132. http://dx.doi.org/10.1590/S0103-863X2002000200009

Simon, T. J., Takarae, Y., Deboer, T., McDonald-McGinn, D. M., Zackai, E. H., \& Ross, J. L. (2008). Overlapping numerical cognition impairments in children with chromosome 22q11.2 deletion or turner syndromes. Neuropsychologia, 46, 82-94. http://dx.doi.org/10.1016/j.neuropsychologia.2007.08.016

Tang, S. X., Yi, J. J., Calkins, M. E., Whinna, D. A., Kohler, C. G., Souders, M. C., ... Gur, R. E. (2014a). Psychiatric disorders in 22q11.2 deletion syndrome are prevalent but undertreated. Psychological Medicine, 44(6), 1267-1277. http:// dx.doi.org/10.1017/S0033291713001669

Tang, S. X., Yi, J. J., Moore, T. M., Calkins, M. E., Kohler, C. G., Whinna, D. A., ... Gur, R. E. (2014b). Subthreshold psychotic symptoms in 22q11.2 deletion syndrome. Journal of the American Academy of Child and Adolescent Psychiatry, 53(9), 999-1000. http://dx.doi.org/10.1016/j.jaac.2014.05.009

Wechsler, D. (2013). Escala Wechsler de Inteligência para Crianças (WISC IV): manual de instruções para aplicação e avaliação (4a ed.). São Paulo: Casa do Psicólogo.

Wong, L. M., Riggins, T., Harvey, D., Cabaral, M., \& Simon, T. J. (2014). Children with chromosome 22q11.2 deletion syndrome exhibit impaired spatial working memory. American Journal on Intellectual and Developmental Disabilities, 119(2), 115-132. http://dx.doi.org/10.1352/1944-7558-119.2.115

Zarchi, O., Diamond, A., Weinberger, R., Abbott, D., Carmel, M., Frisch, A., ... Gothelf, D. (2014). A comparative study of the neuropsychiatric and neurocognitive phenotype in two microdeletion syndromes: Velo-cardio-facial (22q11.2 deletion) and Williams (7q11.23 deletion) syndromes. European Psychiatry, 29(4), 203-210. http://dx.doi.org/10.1016/j. eurpsy.2013.07.001

Zhao, Y., Guo, T., Fiksinski, A., Breetvelt, E., McDonald-McGinn, D. M., Crowley, T. B., ... Morrow, B. E. (2018). Variance of IQ is partially dependent on deletion type among 1,427 22q11.2 deletion syndrome subjects. American Journal of Medical Genetics Part A, 176(10), 2172-2181. http://dx.doi.org/10.1002/ajmg.a.40359

Received: September 10, 2018

Final version: May 10, 2019

Approved: September 5, 2019 